\title{
COMPARISON OF SUCCESS RATE BETWEEN EXTERNAL ROTATION METHOD AND MILCH METHOD FOR REDUCTION OF ACUTE ANTERIOR DISLOCATION OF SHOULDER JOINT
}

\author{
NAVEED ALI SHAIR ${ }^{1}$, AFTAB ANWAR ${ }^{2}$, MUHAMMAD KASHIF ${ }^{3}$, USMAN NAZIR GILL ${ }^{1}$, \\ SHIRAZ MALIK ${ }^{1}$ \\ ${ }^{1}$ Department of Orthopedic Surgery, Lahore General Hospital, Lahore, ${ }^{2}$ Department of Pediatric Gastroenterology, \\ PGMI/AMC/LGH, Lahore, ${ }^{3}$ Department of Orthopedic Surgery Central Park Medical College, Lahore
}

\begin{abstract}
Objective: To compare External Rotation Method with Milch method for reduction of acute anterior dislocation of shoulder joint.

Methods: It was randomized controlled trial. It was conducted at department of Orthopedic Surgery, Services Hospital Lahore, from May 2016 to December 2016.

110 patients of acute anterior dislocation of shoulder joint were randomly distributed into two groups. Reduction of shoulder joint was achieved with External Rotation Method in Group A while Milch method was employed in Group B and their outcomes were compared. Data was entered and analyzed using SPSS for windows (version 21). P-value $<0.05$ was considered significant.

Result: Statistical difference between success rate of External Rotation (72.7\%) and Milch Method (74.5\%), was insignificant $(\mathrm{p}=0.828)$

Conclusion: Though external rotation method is easy to perform, both methods can be used in reduction of acute anterior dislocation of shoulder joint.
\end{abstract}

Keywords: Reduction, Acute anterior dislocation, Shoulder joint.

How to cite this article: Shair NA, Anwar A, Kashif M, Gill UN, Malik S. Comparison of success rate between External Rotation Method and Milch Method for reduction of acute anterior dislocation of shoulder joint. Pak Postgrad Med J 2020;31(3): 128-131

This is an Open Access article distributed under the terms of the Creative Commons Attribution License (http://creativecommons.org/licenses/by/3.0), which permits unrestricted use, distribution, and reproduction in any medium, provided the original work is properly cited.

DOI: https://doi.org/10.51642/ppmj.v31i03.336

Correspondence to: Aftab Anwar, Assistant Professor, Department of Pediatric Gastroenterology, PGMI/AMC/LGH, Lahore, Pakistan.

Email:dr.aftabanwar@gmail.com

\section{INTRODUCTION}

In human body, most commonly dislocated joint is the gleno-humeral joint of shoulder. ${ }^{1}$ Of all major joint dislocations, the shoulder is affected in $60 \%$ cases, and anterior dislocation occurs in 97 percent of all shoulder joint dislocations. ${ }^{2}$ Anterior dislocation of shoulder may occur from direct and indirect trauma by fall on ground and by accidents. ${ }^{3}$ It might be associated with injury to the joint capsule, ligaments, rotator cuff, vascular or neurological structures. These injuries and condition of patient may affect the management of shoulder dislocation. ${ }^{4}$

Various shoulder reduction methods are described in the literature. The popular ones include external rotation method (ERM) amd Milch method. ERM is painless, reliable, effective, not requiring any anesthesia. ${ }^{5}$ Milch method is also painless, safe and reliable method in which position of humerus helps to neutralize deforming muscle forces which helps in reduction. ${ }^{6}$ The comparison of both methods in terms of efficacy and reliability has been done 
by only a few studies. The success rate and outcome of both methods were compared in this study.

\section{METHODS}

After hospital ethical committee approval and consent from patients/guardian of the patients; the study was conducted at the Department of Orthopedic Surgery, Services Hospital, Lahore, from May 2016 to December 2016, comparing two methods (ERM and the Milch method) for close reduction of acute anterior dislocation of shoulder joint, without anaesthesia.

We included 55 cases in each group, by nonprobability consecutive sampling. Sample size of 110 was calculated taking $80 \%$ power of test, significance level as $5 \%$, taking expected percentage of success i.e. $88.46 \%$ with external rotation method and $69.23 \%$ with Milch method. ${ }^{7}$ Demographic profile (name, age, gender and duration of acute dislocation) also obtained. Lottery method was used to randomly divide patients in 2 groups. Patients of either gender who had acute traumatic anterior dislocation of shoulder $(<24$ hours) for first time, with age between 30 to 60 years, were included in the study. Patients who presented 24 hours after dislocation, with poly trauma (on x-ray), hemodynamically unstable (PT > 20 seconds, INR >2 , $\mathrm{Hb}<10 \mathrm{mg} / \mathrm{dl}$ ), with head splitting of proximal humerus fracture, with Neers 3 or 4 part fracture, with generalized joint laxity (on x-ray), with recurrent trauma (taken treatment within 6 months) were excluded. Patients who had glenoid fracture that involved $>25 \%$ open growth plate, were also excluded from study. The procedure was labeled successful when reduction was achieved in first attempt without anesthesia.

In Group A, ERM was applied. Patient was asked to lie down supine on the bed. The involved arm was abducted from the chest wall. After that the elbow was flexed at $90^{\circ}$, flexion of shoulder was done at $20^{\circ}$, patient's wrist was held with one hand while holding elbow with other hand, arm was rotated externally, to bring forearm in the coronal plane. Traction was not applied. After procedure, the arm was gently rotated internally, to bring forearm to lie across the chest.

In Group B, Milch technique was applied. Patients were asked to lie in supine position with head end elevated. The involved arm was slowly abducted and rotated externally, holding at the wrist, to achieve $90^{\circ}$ overhead abduction and $90^{\circ}$ external rotation. In the line of humerus, gentle longitudinal traction was applied. The free hand was placed in axilla, humeral head was felt and pressed laterally and superiorly to achieve reduction.

During the procedure patient was be constantly reassured that no pain would be felt. X-ray was requested to assess the complete reduction. During procedure patient was asked if he/she feels severe pain. If no pain occurred and reduction achieved without anesthesia in first attempt, then success was labeled. All the information was collected through a specially designed proforma (attached).

Data was analyzed using SPSS version 21.Qualitative variables including gender and success rate were expressed in terms of frequencies and percentages while age was expressed as mean and standard deviation. $\mathrm{p}$ value was calculated by Chi Square test.

\section{RESULTS}

We included 110 patients in this study, 55 in each group. There mean age was $46.56 \pm 7.71$ years with age ranging from 31 to 60 years as given in Table I. There were 69 (62.7\%) male patients and 41 (37.3\%) female patients in our cohort. Both groups had no significant statistical difference in terms of age $(p=0.99)$ and gender $(p=0.167)$. History of fall was the most common antecedent event recorded while dislocation on right side was more i.e., 64.5\%. Reduction was achieved in $72.7 \%$ patients employing external rotation method, while it was $74.5 \%$ by Milch method. However, the $\mathrm{p}$ value was insignificant i.e., 0.828 .

Table 1: Comparison of Age and Sex between two groups of reduction methods

\begin{tabular}{lccc}
\hline Variable & $\begin{array}{c}\text { External } \\
\text { Rotation }\end{array}$ & $\begin{array}{c}\text { Milch's } \\
\text { Method }\end{array}$ & $\begin{array}{c}\text { p-value } \\
\text { (Chi-Square } \\
\text { test) }\end{array}$ \\
\hline $\begin{array}{l}\text { Age } \\
\text { Sex }\end{array}$ & $44.55 \pm 8.57$ & $48.58 \pm 6.19$ & 0.99 \\
$\quad$ Male & $31(56.4 \%)$ & $38(69.1 \%)$ & \\
$\quad \begin{array}{l}\text { Female } \\
\text { Success rate }\end{array}$ & $24(43.6 \%)$ & $17(30.9)$ & 0.167 \\
$\quad$ Male & $40(72.7 \%)$ & $41(74.5 \%)$ & \\
$\quad$ Female & $15(27.3 \%)$ & $14(24.5 \%)$ & 0.828 \\
\hline
\end{tabular}

\section{DISCUSSION}

To treat anterior dislocation of shoulder joint, numerous techniques are described in literature. ${ }^{5}$ Traction and/or leverage of the humerus is used. These techniques require considerable force and might cause discomfort to patient. More traditional techniques may cause capsular damage, humeral neck and shaft fractures or axillary nerve injury, 
hence, they are no longer recommended. ${ }^{8}$ ERM and Milch method are easy to perform without anesthesia and both have good success rate. ${ }^{9}$

100 percent success rate cannot be guaranteed by any shoulder reduction method, and a single reduction technique cannot be applied in every shoulder dislocation. ${ }^{10}$ Ideal shoulder reduction method should be painless, simple, effective, rapid and must not cause complications for the patient. Medical services are not overburdened if the reduction manipulation is carried out without sedation or anesthesia. Patient's recovers rapidly and hospital stay also reduces if an affective shoulder reduction method is employed. ${ }^{11}$

We concluded that the success rate of ERM $(72.7 \%)$ and Milch (74.5\%) method of reduction is statistically insignificant ( $\mathrm{p}=0.828$ ). Sapkota $\mathrm{k}$ et al have similar nonsignificant statistical difference (0.09) like our study. The success rate in their study was $88.46 \%$ by ERM and $69.23 \%$ in Milch method. ${ }^{6}$ Gluer O et al compared four different methods (Spaso, Chair, Kocher and Masten) for anterior dislocation of shoulder and similar to our study did not conclude any statistical difference among them. ${ }^{10}$ Our study corroborates the epidemiology of shoulder joint dislocations as described by previous studies. $62.7 \%$ patients of our cohort were male while $37.3 \%$ were female. Similar ratio of $67 \%$ male and $33 \%$ female patients has been described by Solovyova et al. ${ }^{4}$ Mean age in our study was $46.56 \pm 7.71$ years is also similar to 46 years mean age described above study. However, despite the similar ratio of gender $(61.5 \%$ male and $38.5 \%$ female) described by Sapkota et al, their cohort consisted of younger patients with mean age of $27.65 \pm$ 5.50 years which contrasts with our findings.

$64.5 \%$ of patients our patients presented to us after fall. $80.77 \%$ of Sapkota et al also presented with history of fall. But in contrast to above findings, Saw $\mathrm{R}$ et al mentioned contact sport injuries to be the most common cause of shoulder dislocation. ${ }^{12}$ These differences might be due to the active life style of western communities as compared to ours. No complications were recorded. Reduction can be obtained safely by both methods without requirement of anesthesia, decreasing the hazards associated with it. Patients were discharged immediately after reduction, minimalizing health resources burden.

We did not quantify pain during the procedure, which is a shortcoming of our study. Also the study is from a single unit. More elaborated studies involving multiple units at various hospital might have different results from our findings. Although Milch method had a slight statistical dominance in outcome, ERM was easy to perform.

\section{CONCLUSION}

ERM and Milch method have no statistically significant difference in success rate.

\section{CONFLICT OF INTEREST}

The authors declare that there were no conflicting interests.

\section{ETHICAL APPROVAL}

The study was approved from Institutional Review Board of Services Institute of Medical Sciences, Lahore, Pakistan, vide reference No. IRB/2015/190/SIMS, dated December 15, 2015

\section{REFERENCES}

1. Eovaldi BJ, Varacallo M. StatPearls [Internet] StatPearls Publishing; Treasure Island (FL): Dec 3, 2018.

2. Abrams R, Akbarnia H. Shoulder Dislocations Overview. [Updated 2019 Jun 4]. In: StatPearls [Internet]. Treasure Island (FL): StatPearls Publishing; 2019 Jan-. Available from: https://www.ncbi.nlm. nih.gov/books/NBK459125/

3. Farooque K, Khatri K, Dev C, Sharma V, Gupta B. Mechanism of injury and management in traumatic anterior shoulder dislocation with concomitant humeral shaft and ipsilateral scapula fracture: a case report and review of the literature. J Med Case Rep. 2014;8:431. Published 2014 Dec 16. doi:10.1186/1752-1947-8-431.

4. Solovyova O, Shakked R, Tejwani NC. Should All Shoulder Dislocations be Closed Reduced? Assessment of Risk of Iatrogenic Injury in 150 Patients. Iowa Orthop J. 2017;37:47-52.

5. Mario M, Luigi P. The external rotation method for reduction of acute anterior shoulder dislocations. Orthopaed Traumatol. 2009;10:17-20.

6. Sapkota K, Shrestha B, Onta PR, Thapa P. Comparison between external rotation method and milch method for reduction of acute anterior dislocation of shoulder. J Clin Diagn Res. 2015;9(4):RC01-RC3. doi:10.7860/ JCDR/2015/11850.5738

7. Mohammad Jafari Chokan, N., Reihani, H., Pishbin, E. Which technique is better for reduction of anterior shoulder dislocation? External rotation or Milch method. A review of literature. Reviews in Clinical Medicine, 2016; 3(4): 163-165. doi: 10.22038/ rcm.2016.6487.

8. Daya M (2002) Shoulder. In: Marx JA, Hockberger RS, Walls RM (eds) Rosen's emergency medicine. concepts and clinical practice, 5th edn. Mosby Inc, Missouri, pp 576-606 
9. Canale ST, Beaty JH, Phillips BB. Recurrent dislocation in Canley and Beaty: Campbell's Operative Orthopaedics. 11th edition, Philadelphia; Mosby Elsevier, 2007:45:2677-2683

10. Guler O, Ekinci S, Akyildiz F, Timrik U, Cakmak S, Ugras A et al. Comparison of four different reduction methods for anterior dislocation of the shoulder. J Orthop Surg Res. 2015;10:80. Published 2015 May 28. doi:10.1186/s13018-015-0226-4.

11. Johnson G, Hulse W, McGowan A. The Milch technique for reduction of anterior shoulder dislocations in an accident and emergency department.Arch Emerg Med. 1992;9:40-43.

12. Saw R, Finch CF, Samra D, Baquie P, Cardoso T, Hope $\mathrm{D}$ et al. Injuries in Australian Rules Football: An Overview of Injury Rates, Patterns, and Mechanisms Across All Levels of Play. Sports Health. 2018;10(3):208-216. doi:10.1177/1941738117726070

\section{AUTHOURS CONTRIBUTIONS}

NAS: Data collection, write up

AA: Revision, proof reading

MK: Conceptualization and designing of study, write up

UNG Data analysis and interpretation

SM: Reference writing 